\title{
Tax Incentives, Competition and Welfare
}

\author{
Claudio Andre Gondim Nogueira \\ University of Fortaleza (UNIFOR), Fortaleza, Brazil \\ Email: claudioandre@unifor.br
}

Received June 3, 2012; revised July 2, 2012; accepted July 10, 2012

\begin{abstract}
The main objective of this paper is to analyze the impacts of the concession of tax incentives as a tool for entry promotion in a developing region. The simple model and the numerical example presented indicate that the adoption of tax incentives can cause very important effects. The productive structure could be heavily changed and production could increase improving conditions to consumers that benefit from the larger output and lower prices. Furthermore, the need for strategic action by the government in order to increase the chance of success of their development strategies is also emphasized, especially if one considers that firms often behave strategically.
\end{abstract}

Keywords: Tax Incentives; Industrial Structure; Competition; Welfare

\section{Introduction}

Tax incentives are important policy instruments that can be used in different contexts in order to facilitate the achievement of pre-established governmental goals. According to the modern economic literature, tax incentives have been used to stimulate investments in physical and human capital and in new products and technologies (through research and development- $\mathrm{R} \& \mathrm{D}$ - activities), environmental protection, export promotion, and the development of key sectors of an economy, even though their adoption in this case could end up generating unexpected and/or undesirable results in some specific situations (see [1-4]).

Among many other possible cases, it is relevant to discuss one specific use of this type of policy instrument that is becoming increasingly important. Tax incentives have also been used in order to facilitate the attraction of new firms to a country or region. This case is particularly important if less-developed countries or regions are considered basically because, in general, tax incentives are used in this context to compensate for considerable deficiencies in the existing infrastructure. More specifically, given the existing conditions, if tax incentives are not conceded fewer would be the incentives that new firms will have to enter that specific market.

In fact, many countries throughout the world use this type of mechanism in order to attract foreign companies to their markets, especially in specific areas of the country that are less developed. Among these countries one can mention Brazil, Canada, US, Vietnam, Malta, Greece, India, etc.

When tax incentives are used as instruments for entry promotion, the diversity of approaches used is significant, since several different tax-incentive schemes and contexts can be analyzed. Hence, in this context, the point that must be emphasized is that the free international movement of goods and capital could mean free international movement of tax bases. In other words, the desire to attract new investments (plants) to a country or region through the concession of tax incentives may lead to a process of tax competition among these countries or regions (see e.g. [5]).

It is also important to emphasize that such policy of attraction of new firms through the concession of tax incentives often alters the structure of the existing industry by affecting the profitability and the competitiveness of the already established firms. Furthermore, the concession of such incentives has considerable implications to welfare that cannot be forgotten. This remark becomes even more important as one considers that tax competition exists and affects the decisions of the agents involved.

Then, the most important lesson that can be obtained from this discussion is that the impacts of this type of policy in question, especially in a context where there is tax competition among countries or regions, are a priori indeterminate, i.e., different models could give different explanations and predictions according to the assumptions made and the methodology chosen.

Thus, the main objective of this paper is exactly to analyze the impacts of the concession of tax incentives as a tool for entry promotion in a developing region, considering the effects over the existing productive structure as well as over social welfare.

For that intent, it will be considered an entry-deterrence framework where the incumbent firm can actually compete with the entrant in another way rather than predatory 
price competition, which could often lead to bad outcomes both to the firms and to the region in consideration (see [6-10]).

The model presented here is in fact based on a simplified version of the Dixit-Spence framework discussed by Fudenberg and Tirole [8], and Romp [9]. The use of this framework is indeed appropriate in this context because it enables the analysis of the decision process of the companies involved and, at the same time, the analysis of the behavior of the government as it attempts to maximize total welfare when it decides how much incentives to concede.

The model considers the case where there are two companies in the analysis, one that is already established in the market in consideration (the incumbent firm) and the other that is deciding whether or not it should enter in that market (the entrant firm). More specifically, it is contemplated the case where the incumbent firm can invest in new organizational techniques and/or in new productive processes as it tries to reduce its costs of production and to become more competitive.

Dixit [7] and Gabszewicz [11], for example, discuss the importance of the investment in the entry-deterrence framework. The main concern of these authors is centered on how the incumbent firm will define its optimal productive capacity in a two-period game in order to deter the entry of a new firm in the market. The approach used in this paper is, however, closer to the examples presented by Fudenberg and Tirole [8] and Tirole [12] where the investment made in fact reduces the marginal cost of the firm (of the incumbent in this case) and allows it to become more competitive.

Thus, this paper is divided as follows. In Section 2, the basic model and fundamental assumptions will be presented. The basic model contemplates only the behavior of the entrant and incumbent firms. The purpose of this model is to analyze how the firms will react given the amount of incentives conceded by the government. In Section 3 , the role of the government will be analyzed as the decision of how much incentives to concede will become endogenous as it tries to maximize a specific welfare function whose properties and characteristics will be presented opportunely. Additionally, the importance of the existing infrastructure will be emphasized and the model will be adapted. Since the problem that the government faces is somewhat difficult to solve then, in Section 4, a numerical example will be used in order to verify how the government should behave. Finally, concluding remarks and references will be presented.

\section{Basic Model and Assumptions}

Consider that the government of a developing region is trying to attract firms to the region. The government's basic intention is to stimulate the expansion of key sectors of the local economy and to promote an overall increase in the total output produced. The people of the region are expected to benefit from this process as they are able to increase their consumption levels and pay lower prices as competition increases in the market.

Assume for simplicity that in a strategic sector of this economy only one firm supplies a specific product and there are no close substitutes. This firm will be referred to as the incumbent firm (and denoted by $I$ ). The demand for this product in question is given by $P(Q)=b-Q$, if $Q<b$, or by $P(Q)=0$, otherwise. The total cost incurred by the incumbent to produce $q_{I}$ units of output is given by

$$
C_{I}\left(q_{I}\right)=\left(c_{I}+\tau\right) \cdot q_{I}
$$

where $c_{I}$ represents the cost to produce an additional unit of the good and $\tau$ is a tax that the firm pays to the government for every unit produced (it is exogenously determined). It is important to mention that $c_{I}$ depends both on the technology and on the effectiveness of the organizational techniques that the firm adopts. It is expected that more advanced technologies and more efficient organizational techniques would yield lower values of $c_{I}$.

Given the demand of the market, the incumbent firm will earn profits given by

$$
\pi_{I}^{m}=\left(b-q_{I}^{m}\right) \cdot q_{I}^{m}-\left(c_{i}+\tau\right) \cdot q_{I}^{m}
$$

where $m$ indicates that firm $I$ is a monopolist in this market. Then, this firm will try to maximize its profits by choosing the optimal amount that it should produce. If an interior solution is assumed (i.e., if $0<q_{I}^{m}<\infty$ ), then the first-order condition for profit maximization implies that the optimal quantity that the incumbent will produce is given by

$$
q_{I}^{m}=(1 / 2) \cdot\left(b-c_{I}-\tau\right)
$$

and the incumbent will earn profits of

$$
\pi_{I}^{m}=\left(q_{I}^{m}\right)^{2}=(1 / 4) \cdot\left(b-c_{I}-\tau\right)^{2}
$$

The problem with this market structure is that in developing regions it is often the case that firms operate with high marginal costs because there are practically no incentives to change the ongoing situation. As a result, according to expressions (3) and (4), the output produced will be relatively small while the market price and the monopolist profits would be somewhat high. This is indeed not a very good scenario because consumers cannot consume as much as they would like to (prices are high) and the government will have low tax revenues (because output is small).

Then, the government will try to attract new firms to this market hoping that by doing so competition will drive output up and prices down. One mechanism that is often 
used to promote entry is the concession of tax incentives to the entrant firm (denoted by $E$ ). This concession is usually temporary and after the period stipulated this firm will decide if it is going to remain in the market or search for new opportunities elsewhere.

Assuming that installation costs are sunk, with the concession of incentives, the total cost of the entrant to produce $q_{E}$ units of output is given by

$$
C_{E}\left(q_{E}\right)=\left(c_{E}+\tau-\delta\right) \cdot q_{E}
$$

where $\delta$ represents the tax incentives (see $[13,14])$. Assume that $\delta \in(0, \bar{\delta}]$ and that $\bar{\delta} \leq \tau$. This condition implies that there is a limit to the concession of such incentives, often determined by law, and that it cannot exceed the value of the tax charged.

If the entrant firm effectively enters the market, then it should be the case that $Q=q_{I}+q_{E}$, and then it will have profits equal to

$$
\pi_{E}=\left(b-q_{I}-q_{E}\right) \cdot q_{E}-\left(c_{E}+\tau-\delta\right) \cdot q_{E}
$$

The problem is that the incumbent firm will not always simply accept the entrance of another firm without a proper reaction, i.e., the incumbent firm will try to deter the entry. One possible way to compete with the entrant would be to start a price war, which often leads to inefficient results (see $[8,9]$ ).

Hence, a credible entry deterrence strategy that the incumbent could choose would be to invest in new technologies, new production processes, and new organizational techniques, i.e., the incumbent could make an investment $(\phi)$ that would lower its marginal costs (see $[8,12])$. More specifically, it should be the case tha $c_{I}^{\prime}<c_{I}$ where the firm invests a determinate amount, say $\phi^{*}$ (refer to this process as the cost-reducing effect). Then, if this is the case, then the incumbent will have profits equal to

$$
\pi_{I}=\left(b-q_{I}-q_{E}\right) \cdot q_{I}-\left(c_{I}^{\prime}+\tau\right) \cdot q_{I}-\phi^{*}
$$

where $\phi^{*}$ represents the investment made (with $\phi^{*}>0$ ). Otherwise, i.e., when $\phi^{*}=0$, it should be the case that

$$
\pi_{I}=\left(b-q_{I}-q_{E}\right) \cdot q_{I}-\left(c_{I}+\tau\right) \cdot q_{I}
$$

Finally, if entry is effectively deterred, first assume that the entrant could earn profits of $\tilde{\pi}$ in some other region without the concession of incentives, or that $\tilde{\pi}$ would be the guaranteed return that the firm would have if it invested in financial markets the same amount of money needed to build a new plant. And, in this case, consider also that the incumbent firm could decide whether to invest or not. It could perceive the investment as a way to becoming more efficient and, consequently, more profitable. Hence, in case the investment is not made, the incumbent will have profits as shown by expression (4). Otherwise, profits will be equal to

$$
\pi_{I}^{m^{\prime}}=\left(q_{I}^{m^{\prime}}\right)^{2}-\phi^{*}=(1 / 4) \cdot\left(b-c_{I}^{\prime}-\tau\right)^{2}-\phi^{*}
$$

Thus, given all these fundamental assumptions and expressions, then the best way to analyze this problem in detail would be to put it in an extensive game form where all possible outcomes could be investigated.

The basic game in question could then be explained as follows. At $t=0$ ( $t$ denotes the time period in question), the government will offer tax incentives equal to $\delta$ to a firm (the entrant) with marginal cost given by $c_{E}$ (since it is considered the full information case, it is implicitly assumed that knowing the true cost of the entrant is costless, and that this information is freely spread throughout the economy, because the government cannot keep secrets). Since the market demand is constant over time and production in previous periods could be considered public information, one could easily infer the cost of the incumbent, by rearranging expression (3). Then, at $t=1$, the entrant will either enter the market or not. Represent these strategies by $e$ and $\tilde{e}$, respectively. Finally, at $t=$ 2 , if the entry is confirmed, then both firms will compete as in the Cournot model of duopoly (see $[8,9,15])$ as the incumbent firm will either accommodate $(a)$ or fight $(f)$ as described before. And, if the entry is not confirmed, the incumbent firm will remain the monopolist in that market and will decide whether or not to make the investment described before.

In the case that $\{\tilde{e}, a\}$ is the outcome of the game, even if the incumbent accommodates the entrant will not have enough incentives to enter the market. This case could be possible basically if $\delta$ is not large enough and/or $c_{E}$ is larger than $c_{I}$. And, in the case that the outcome is $\{\tilde{e}, f\}$, the incumbent's strategy to deter the entry will be effective (the factors just mentioned could also be important in this case). In both cases the entrant will not be able to earn profits greater than $\tilde{\pi}$ and, therefore, will have no incentives to enter the market.

But, when the entrant effectively enters the market, then if the incumbent firm accommodates, i.e., when the outcome of the game is $\{e, a\}$, they will, respectively, receive profits (derived from profit maximizing conditions and assuming interior solutions) equal to

$$
\pi_{E}^{a}=\left(q_{E}^{a}\right)^{2}=(1 / 9) \cdot\left(b-2 c_{E}+c_{I}-\tau+2 \delta\right)^{2}
$$

and

$$
\pi_{I}^{a}=\left(q_{I}^{a}\right)^{2}=(1 / 9) \cdot\left(b-2 c_{I}+c_{E}-\tau-\delta\right)^{2}
$$

But, if the incumbent fights, the outcome of the game will be $\{e, f\}$ and the payoffs will be

$$
\pi_{E}^{f}=\left(q_{E}^{f}\right)^{2}=(1 / 9) \cdot\left(b-2 c_{E}+c_{I}{ }^{\prime}-\tau+2 \delta\right)^{2}
$$

and 


$$
\pi_{I}^{f}=\left(q_{I}^{f}\right)^{2}-\phi^{*}=(1 / 9) \cdot\left(b-2 c_{I}{ }^{\prime}+c_{E}-\tau-\delta\right)^{2}-\phi^{*}
$$

It is important to notice that, in both cases, the profits of the incumbent are decreased because of the incentives received by the entrant that is clearly beneficiated. Furthermore, profits will decrease the higher are their own costs and increase the higher are the other's costs.

The fundamental point of the analysis is that the government would like to induce the outcomes where the entrant enters the market while the incumbent will fight or not (it wants to avoid the case that entry is effectively deterred). Specifically, since there is full information, the government could solve the game by backward induction and then offer at $t=0$ the amount of incentives necessary to induce one of the desired outcomes, provided that $\delta \in(0, \bar{\delta}]$.

At this point it is difficult to clearly specify which of the desired outcomes $(\{e, a\}$ and $\{e, f\})$ will be chosen by the government because this choice depends on welfare considerations that will only be discussed in detail in Section 3. If this decision depended solely on efficiency criteria, however, it would be reasonable to consider that the government would be more inclined to induce the outcome $\{e, f\}$ because entry would not be deterred whereas the incumbent firm would improve its levels of productive efficiency as it reduces its marginal costs.

Hence, which are the conditions that will guarantee that one of the desired outcomes will be a sub-game perfect Nash equilibrium (SPNE) of this game? Before answering this fundamental question, the decision-making process of both the incumbent and the entrant should be analyzed according to parameters' values. Note that since the equilibrium of this game will be determined by backward induction, then it is important to fully analyze the behavior of the incumbent firm first and, afterwards, analyze the behavior of the entrant given the expected incumbent's strategy.

Proposition 1. Suppose there is entry. Then, given the value of $\delta$, the incumbent will (a) choose to fight if and only if $0<\phi^{*}<\mathrm{A}$, and (b) choose to accommodate if and only if $\phi^{*} \geq \mathrm{A}$, where

$$
\mathrm{A}=(4 / 9) \cdot\left[b-\left(c_{I}+c_{I}^{\prime}\right)+c_{E}-\tau-\delta\right] \cdot\left[c_{I}-c_{I}^{\prime}\right]
$$

Proof. If there is entry, then the incumbent firm will decide to fight if an only if $\pi_{I}^{f}>\pi_{I}^{a}$. Hence, according to expressions (11) and (13), and since by assumption $\phi^{*}>0$ when the incumbent fights, this condition would imply that

$0<\phi^{*}<(4 / 9) \cdot\left[b-\left(c_{I}+c_{I}^{\prime}\right)+c_{E}-\tau-\delta\right] \cdot\left[c_{I}-c_{I}^{\prime}\right]=\mathrm{A}$

And, thus, the incumbent will choose to accommodate if and only if $\pi_{I}^{f} \leq \pi_{I}^{a}$, which would imply that $\phi^{*} \geq \mathrm{A}$.

\section{(Q.E.D.)}

This proposition, as in Fudenberg and Tirole [8], states that fight should be a dominant strategy for the incumbent firm if and only if the level of investment necessary to make it more competitive is not sufficiently high. More specifically, in this case, given the value of the incentives conceded by the government, even though the incumbent will not be capable of deterring the entry it could pay off to fight anyway because the investment made could generate higher profits to the incumbent than if it had just accommodated the entry. However, if the necessary level of investment is too high, then it could drive profits down.

At this point a very important question would be the following: if the government offered very high tax incentives then how would this affect the reaction by the incumbent firm? One could think a priori that higher levels of incentives would automatically lead to the reaction by the incumbent firm basically because high incentives would negatively affect its reaction function forcing it to produce less. But, should this be necessarily true for all levels of $\delta$ ? As expression (14) indicates as $\delta$ increases $A$ will decrease. Thus, in accordance with Proposition 1, by offering high levels of incentives the government could actually discourage the reaction by the incumbent firm.

Thus, in general, one could establish a range of values of $\delta$ in which the incumbent firm will be stimulated to react (as long as the condition $0<\phi^{*}<\mathrm{A}$ is satisfied). In this range, the incumbent firm will choose to fight the entry until $\delta$ reaches a threshold, say $\hat{\delta}$. More specifically, one should have that

$$
\hat{\delta}=b-\left(c_{I}+c_{I}^{\prime}\right)+c_{E}-\tau-(9 / 4) \cdot\left[\phi^{*} /\left(c_{I}-c_{I}^{\prime}\right)\right]
$$

And, if $\hat{\delta}<\bar{\delta}$, then it is possible to define another range of values for $\delta$ where the incumbent firm will decide to accommodate the entry (i.e., Proposition 1a can no longer be satisfied). More specifically, this would happen when $\hat{\delta} \leq \delta \leq \bar{\delta}$.

Notice that this discussion above is about possible scenarios (consider the case where these situations described are simultaneously possible as the benchmark case). Certainly, more situations may emerge according to parameter values, but the benchmark case actually gives a good interpretation on how the incumbent firm should behave in general given the level of incentives conceded by the government. But, what if entry is not confirmed?

Proposition 2. Suppose entry is not confirmed. Then, the incumbent will a) choose to invest (fight) if and only if $0<\phi^{*}<\Gamma$, and b) choose not to invest (accommodate) if and only if $\phi^{*} \geq \Gamma$, where

$$
\Gamma=(1 / 4) \cdot\left[2 b-\left(c_{I}^{\prime}+c_{I}\right)-2 \tau\right] \cdot\left[c_{I}-c_{I}^{\prime}\right]
$$

Proof. If entry is not confirmed, then the incumbent firm will decide to fight if and only if $\pi_{I}^{m^{\prime}}>\pi_{I}^{m}$. Hence, 
according to expressions (9) and (4), this condition would imply that

$$
0<\phi^{*}<(1 / 4) \cdot\left[2 b-\left(c_{I}^{\prime}+c_{I}\right)-2 \tau\right] \cdot\left[c_{I}-c_{I}^{\prime}\right]=\Gamma
$$

And, the incumbent will choose not to invest if and only if $\pi_{I}^{m^{\prime}} \leq \pi_{I}^{m}$, which would imply that $\phi^{*} \geq \Gamma$. (Q.E.D.)

The interpretation of this proposition is very similar to the one given for Proposition 1. More specifically, as a monopolist, the incumbent will invest if and only if the level of investment necessary to make it more competitive is not sufficiently high so that it could become more profitable. But, differently from Proposition 1, this decision is completely independent from the level of incentives granted by the government. Hence, for simplicity, consider that in the benchmark case the investment by the monopoly is always feasible if entry is not confirmed.

Thus, after analyzing how the incumbent firm would react, then it is possible to establish the conditions that will guarantee that the entry will be effectively effectuated. More specifically, as the government offers the amount of tax incentives, the entrant will be able to anticipate which one will be the strategy chosen by the incumbent firm and then it would be able to decide if entry is the best option.

Proposition 3. Given $\delta \in(0, \bar{\delta}]$, if $\pi_{I}^{f}>\pi_{I}^{a}$ then the entrant will effectively enter the market if and only if $\delta>\max \left\{0, B^{\prime}\right\}$. And, if $\pi_{I}^{f} \leq \pi_{I}^{a}$ then the entrant will effectively enter the market if and only if $\delta>\max \{0, B\}$, where

$$
B^{\prime}=(1 / 2) \cdot\left(3 \sqrt{\tilde{\pi}}-b-c_{I}^{\prime}+2 c_{E}+\tau\right)
$$

and

$$
B=(1 / 2) \cdot\left(3 \sqrt{\tilde{\pi}}-b-c_{I}+2 c_{E}+\tau\right)
$$

Proof. By assumption $\delta \in(0, \bar{\delta}]$. Then, if $\pi_{I}^{f}>\pi_{I}^{a}$, in accordance with Proposition 1, the entrant will know that fight would be a dominant strategy for the incumbent firm and then the entrant will effectively enter the market if and only if $\pi_{E}^{f}>\tilde{\pi}$, which implies that

$$
\delta>\max \left\{0,(1 / 2) \cdot\left(3 \sqrt{\tilde{\pi}}-b-c_{I}{ }^{\prime}+2 c_{E}+\tau\right)\right\}
$$

And, if $\pi_{I}^{f} \leq \pi_{I}^{a}$, to accommodate would be a weakly dominant strategy for the incumbent firm and then it will effectively enter the market if and only if $\pi_{E}^{a}>\tilde{\pi}$, which would imply that

$$
\delta>\max \left\{0,(1 / 2) \cdot\left(3 \sqrt{\tilde{\pi}}-b-c_{I}+2 c_{E}+\tau\right)\right\} \cdot(\text { Q.E.D. })
$$

From this proposition one is able to conclude that only for high enough levels of incentives the entrant will effectively enter the market. In other words, the firm will only enter if the incentives are high enough to guarantee profits greater than $\tilde{\pi}$ even when the incumbent firm chooses to fight.

At this point, since $c_{I}>c_{I}^{\prime}$, one should notice that $B<B^{\prime}$. Furthermore, in accordance with Proposition 3, one should consider that the condition given by expression (17) will be binding only when $0<\delta<\hat{\delta}$. Similarly, the condition given by expression (18) will be binding when $\hat{\delta} \leq \delta \leq \bar{\delta}$.

Thus, given parameter values and considering the benchmark case discussed before, the infimum of the possible values of $\delta$ that would stimulate the entry of the firm $\left(\delta^{\mathrm{E}}\right)$ could also be inferred. More precisely, one should have that (see the Equation (19) below).

It is also important to notice that in this benchmark case three equilibria for this game are possible. More specifically, if $0<\delta \leq \delta^{\mathrm{E}}$, the incumbent firm will choose to fight, but the entrant will have no interest in entering the market because the level of incentives conceded is not high enough to grant it profits higher than $\tilde{\pi}$ (the entry will be deterred). Therefore, the sub-game perfect Nash equilibrium of this game will be given by $\{\tilde{e}, f\}$ in this case. If $\delta^{\mathrm{E}}<\delta<\hat{\delta}$, then the entrant will have incentives to enter the market in despite the fact that the incumbent would still try to deter the entry. Hence, the SPNE of the game will be given by $\{e, f\}$ in this case. And, finally, if $\hat{\delta} \leq \delta \leq \bar{\delta}$, the entry will not be deterred nor will the incumbent firm have incentives to invest in new technologies, new productive processes, and more efficient organizational techniques, as explained before. Thus, in this case, the SPNE of this game would be given by $\{e, a\}$.

Certainly, according to parameter values, other possible scenarios could be analyzed. But, the benchmark case discussed above already provides a good intuition of how the model works when the decisions of both the incumbent and the entrant are considered given the amount of tax incentives conceded by the government.

The next logical step is, therefore, to consider how the government should choose the optimal level of incentives that it would concede to the entrant. According to this analysis above, the government is able to induce the outcome of the game as it sets the value of $\delta$. But, at this point, it is not possible to specify exactly what the value of $\delta$ should be. As mentioned before, the choice of $\delta$ and, therefore, the outcome of the game will depend on welfare implications and/or on other factors. And, this is exactly the analysis that will be made in the following section.

\section{Welfare Analysis}

In general, the basic intent of the government when it offers tax incentives is to attract firms to the region in

$$
\delta^{E}=\operatorname{Inf}\left\{\delta \in(0, \bar{\delta}] \text { s.t. } \pi_{E}^{f}>\tilde{\pi} \text { if } \pi_{I}^{f}>\pi_{I}^{a} \text { or } \pi_{E}^{a}>\tilde{\pi} \text { if } \pi_{I}^{f} \leq \pi_{I}^{a}\right\}
$$


consideration and increase total output produced. Overall conditions to society are then supposed to improve as lower prices would be charged for the good in question as competition increases (due to the entry of a new firm in the market).

As already mentioned, when the government pursues this type of policy, in accordance to the model presented before, two types of outcomes would be desired a priori, $\{e, a\}$ and $\{e, f\}$. Additionally, it was shown that the government is able to induce one of these outcomes by choosing the amount of tax incentives that should be conceded. Then, which one should the government choose? Certainly this choice should depend on efficiency criteria, i.e., it should depend on how efficiently firms produce the good in consideration. In this sense, probably $\{e, f\}$ would be the best outcome since the incumbent firm would be induced to improve its production processes and organizational techniques even though it is not able to deter the entry. But, is this outcome really the best one to society? That is why welfare implications of such policy should also be reckoned.

One interesting and more comprehensive way to think about the effects on welfare is to consider the impacts of the concession of tax incentives on three important variables: consumer surplus $(C S)$, total profit $(\Pi)$ and tax revenues $(T)$. The consumer surplus and total profits would provide measures of how consumers and producers are respectively affected by this type of policy, while tax revenues will be important to ascertain whether or not this policy represents a burden to society as the government may have its ability to provide public goods compromised by the effort to attract new firms to the region or country in consideration. The results obtained should then be compared to the situation where only one firm is in the market (as it was initially). Then the government will be able to assess if the policy adopted was really effective in improving overall conditions to society.

The proposed format for the welfare function in all possible cases is given by

$$
W_{i}=C S_{i}+\Pi_{i}+T_{i}
$$

where $i \in\left\{m, m^{\prime}, a, f\right\}, m$ represents the case where the incumbent firm is the sole producer of the good in that market but does not invest, while $m^{\prime}$ is the case where the investment is made. $a$ represents the case where there is entry but the incumbent decides to accommodate, and, finally, $f$ represents the case where there is entry and the incumbent decides to fight.

There could be, however, differences on the definition of each term of the welfare function according to the case considered. The detailed discussion about each of these terms follows.

First, since the demand of this market is given by $P(Q)=b-Q$, if $Q<b$, and $P(Q)=0$, otherwise, then, in accordance with Gibbons [15], the consumer surplus for each case considered could then be defined as

$$
C S_{i}=\int_{o}^{Q_{i}} p d Q-p Q_{i}=\frac{Q_{i}^{2}}{2}
$$

As expression (21) shows, the consumer surplus increases monotonically with the total output produced. Therefore, the outcome that would generate the highest level of output would also yield the highest consumer surplus. In this sense, the government has incentives to induce the outcome that is more efficient in terms of production. And, these incentives tend to be even greater if one considers that profits are also intrinsically related to the amount of output produced (at least when the Cournot model of duopoly is considered).

Then, the total profit function could be defined for the monopoly cases as

$$
\Pi_{M}=\pi_{I}^{M}=\left(q_{I}^{M}\right)^{2}-\phi
$$

where $M \in\left\{m, m^{\prime}\right\}, \phi=0$ when $M=m$, and $\phi=\phi^{*}$ when $M=m^{\prime}$. And, for the other cases, one should have that

$$
\Pi_{j}=\pi_{I}^{j}+\pi_{E}^{j}=\left(q_{I}^{j}\right)^{2}-\phi+\left(q_{E}^{j}\right)^{2}
$$

where $j \in\{a, f\}, \phi=0$ when $j=a$, and $\phi=\phi^{*}$ when $j$ $=f$.

Finally, the tax revenue function for the monopoly case is given by

$$
T_{M}=(1+\lambda) \cdot \tau \cdot q_{I}^{M}
$$

where as for the other cases on should have that

$$
T_{j}=(1+\lambda) \cdot\left[\tau \cdot\left(q_{I}^{j}+q_{E}^{j}\right)-\delta \cdot q_{E}^{j}\right]
$$

One could notice that the tax revenues, in both cases, is multiplied by an additional term, $(1+\lambda)$, with $\lambda \geq 0$. This parameter, $\lambda$, is somewhat related to what is usually called in public finance theory the shadow cost of public funds. According to Laffont and Tirole [16] and Atkinson and Stiglitz [17], this concept shows that for each dollar that the government raises society actually pays $(1+\lambda)$ dollars, i.e., it shows that society could perceive that the real opportunity cost of public funds could be in fact greater than its monetary cost. The use of this concept is appropriate in situations as the one described by Laffont and Tirole [16] where the government uses public funds to finance a firm's deficit. In this case, it is straightforward to verify that the government is taxing consumers and giving up valuable resources that could have been used to finance the provision of public goods and, therefore, the cost to society may be in fact greater than the monetary cost, especially in less developed countries or regions where the basic infrastructure available (basic 
education, health care, etc.) is in many cases extremely deficient.

In the present study, however, this is not necessarily the case. In fact, in developing countries or regions, when the government concedes tax incentives it gives up part of the potential tax revenues had the new firm entered the market on its own in exchange for increments on consumer and producer surplus, but tax revenues could still be greater than in the monopoly case. The important point is that $\lambda$ should represent that every dollar the government receives may value much more to society than the monetary value that the firms pay according to the infrastructure available in the country or region considered, because the poorer the country or region is, the more important should be considered the resources obtained by the government through taxation.

Hence, from now on $\lambda$ should be referred to as the shadow value of public funds. And, more specifically, the case where $\lambda=0$ represents a country or region whose basic infrastructure is already satisfactory. But, in cases where $\lambda>0$, the greater this term is the more deficient is the infrastructure and, therefore, the more valuable are the public funds obtained.

Thus, after these important comments, it is possible to re-write expression (20) according to the cases contemplated by the model. More specifically, for the monopoly case one should have that

$$
W_{M}=(3 / 2) \cdot\left(q_{I}^{M}\right)^{2}+(1+\lambda) \cdot \tau \cdot q_{I}^{M}-\phi
$$

and, for the other two cases, one should have that

$$
\begin{aligned}
W_{j}= & (3 / 2) \cdot\left[\left(q_{I}^{j}\right)^{2}+\left(q_{E}^{j}\right)^{2}\right]+q_{I}^{j} q_{E}^{j} \\
& +(1+\lambda)\left[\tau\left(q_{I}^{j}+q_{E}^{j}\right)-\delta q_{E}^{j}\right]-\phi
\end{aligned}
$$

At this point it is possible to properly address the question posed on the beginning of this section: which outcome of the game should the government induce? Before that, however, it would be of the utmost importance to further investigate the relationship between social welfare and the existing infrastructure. Without any doubts, infrastructure can become an even more decisive variable in the model, especially when one considers that a firm's decision to open a new factory in a determinate region depends not only on the tax incentives received, but also on other factors. And, these other factors can be important because they probably affect the costs of production of both firms (see $[18,19]$ ).

In Section 2 it was mentioned that $c$ should reflect how efficiently the firm is able to produce the good according to the technology and the organizational techniques that the firm adopts. But, in reality, one should also consider how well the firm uses these factors according to the characteristics of the region that it is located. Hence, other factors that may affect the cost of the firms are, for example, the availability of basic infrastructure (electricity, water, highways, etc.), the educational level of the workforce available, the proximity to other firms (e.g. suppliers), the proximity to consumers, transportation costs, the firm experience in that specific market, etc. For simplicity, call this set of factors infrastructure.

Then, it is reasonable to assume that $c_{h}=\omega_{h} \cdot \kappa_{h}$, with $h \in\{I, E\}$, where $\kappa_{h}$ is the cost associated with the technology and organizational techniques in use by firm $h$ and $\omega_{h}$ is a parameter $\left(\omega_{h}>0\right)$ that captures how efficiently the firm is able to use its technology according to the specific regional characteristics or according to the infrastructure available. Therefore, from now on, $c_{h}$ will be referred as the effective marginal cost of firm $h$.

As discussed previously, the impacts of the infrastructure on tax revenues and welfare is measured by the shadow value of public funds, $\lambda$. Hence, in order to unify these two approaches in a simple way, one must make the following relevant assumptions:

Fundamental Assumption 1. There is a positive and significant correlation between $\lambda$ and $\omega_{h}$, with $h \in\{I, E\}$.

Fundamental Assumption 2. The correlation between $\lambda$ and $\omega_{h}$, could be represented by a linear equation like $\omega_{h}=\psi_{h}+v_{h} \cdot \lambda$, with $\psi_{h}, v_{h} \geq 0$.

Given these assumptions, then the model presented so far can be considered as a particular case of this more general model (where costs are related to the existing infrastructure), when $\psi_{h}=1$ and $v_{h}=0$.

Thus, considering these modifications, the answer to the fundamental question of this section will depend basically on which case would yield a higher level of total welfare. More specifically, the government will try to choose the outcome that locally maximizes welfare according to parameter values. It is also important to notice that the government cannot affect the level of welfare in the monopoly case, since none of the parameters involved can be directly changed by the government. But, it could certainly affect the level of total welfare on the other two cases as it determines the amount of tax incentives that will be granted to the entrant. Therefore, in each of these cases, the government will try to maximize $W_{j}$ by choosing the optimal level of $\delta$.

The optimization problem that the government faces may assume different forms according to the different possible outcomes. More specifically, when incumbent firm fights the entry, this maximization problem should be written as

$$
\begin{aligned}
& \operatorname{Max}_{\delta} W_{f}=(3 / 2) \cdot\left[\left(q_{I}^{f}\right)^{2}+\left(q_{E}^{f}\right)^{2}\right]+q_{I}^{f} q_{E}^{f} \\
&+(1+\lambda)\left[\tau\left(q_{I}^{f}+q_{E}^{f}\right)-\delta \cdot q_{E}^{f}\right]-\phi \\
& \text { s.t. } q_{I}^{f} \geq 0, \quad q_{E}^{f} \geq 0, \text { and } \delta^{E}<\delta<\hat{\delta} .
\end{aligned}
$$

And, when it accommodates the entry, the maximization 
problem is given by

$$
\begin{aligned}
& \underset{\delta}{\operatorname{Max}} W_{a}=(3 / 2) \cdot\left[\left(q_{I}^{a}\right)^{2}+\left(q_{E}^{a}\right)^{2}\right]+q_{I}^{a} q_{E}^{a} \\
&+(1+\lambda)\left[\tau\left(q_{I}^{a}+q_{E}^{a}\right)-\delta \cdot q_{E}^{a}\right] \\
& \text { s.t. } q_{I}^{a} \geq 0, \quad q_{E}^{a} \geq 0, \text { and } \hat{\delta} \leq \delta \leq \bar{\delta} .
\end{aligned}
$$

The results should then be compared to each other and to $W_{M}$, in order to verify which one would yield the highest level of welfare. With this information, then the government will be able to ascertain if this type of policy is justifiable (i.e., if $W_{j}>W_{M}$ ) and which outcome should then be induced according to the value of $\delta$.

The drawback of this type of optimization problem that involves a series of nonlinear constraints is that it is virtually impossible to find an algebraic solution for $\delta$ in terms of the other parameters of the model. Therefore, a numerical example will be used to illustrate how the proposed model works. In this example all the parameters of the model will be fixed, and variations will be attributed to $\lambda$, i.e., it will be considered different levels of infrastructure (more specifically, the values chosen for $\lambda$ were $0.5,1.0$, e 2.0 ). Then, the optimal value of $\delta$ will be inferred in each case analyzed.

\section{A Numerical Example}

Assume that the demand of this market is given by $P(Q)=12-Q$, if $Q<12$, and $P(Q)=0$, otherwise, and that $\tau=1, \bar{\delta}=0.75, \tilde{\pi}=10, \kappa_{E}=\kappa_{I}=1.50$, $\kappa_{I}^{\prime}=1.00$, and $\phi^{*}=2.10$.

Assume also that $\omega_{I}=0.94+0.06 \lambda$ and that $\omega_{E}=0.98$ $+0.08 \lambda$. These expressions show how the firms' costs are affected by the existing infrastructure. One can notice that the entrant is more affected by the conditions available since $\psi_{E}>\psi_{I}$, and since $v_{E}>v_{I}$ (The parameter $v_{h}$ measures the change in $\omega_{h}$ due to variations in the available infrastructure). In other words, for the same value of $\lambda$, the effective marginal cost of the entrant will be greater than the incumbent's. The justification for such distinction is based on the differences of experience that these firms have. That is, since the incumbent firm is already established in that market, then it is reasonable to assume that it can make better use of the regional characteristics of the country or region in question since it is already adapted to the existing conditions.

Then, it is possible to perform calculations considering the impacts of the infrastructure on costs. Table 1, below, shows the results obtained.

As Table 1 shows, the case study presents a series of relevant insights. First, given parameter values, it is straightforward that the welfare levels attained with the concession of incentives are always greater than the levels when entry is deterred (i.e., $W_{j}>W_{M}$ in all cases). Hence, this policy is justifiable.
Table 1. Numerical example-Results of the calculations.

\begin{tabular}{cccc}
\hline & $\lambda=0.50$ & $\lambda=1.00$ & $\lambda=2.00$ \\
\cline { 2 - 4 }$c_{I}$ & 1.46 & 1.50 & 1.59 \\
$c_{I}{ }^{\prime}$ & 0.97 & 1.00 & 1.06 \\
$c_{E}$ & 1.53 & 1.59 & 1.71 \\
$\delta^{E}$ & 0.28 & 0.33 & 0.42 \\
$\hat{\delta}$ & 0.37 & 0.64 & 1.14 \\
$\delta^{*}$ & 0.29 & 0.34 & 0.43 \\
$W_{J}$ & 51.46 & 53.67 & 57.64 \\
$W_{M}$ & 43.15 & 45.40 & 49.86 \\
\hline
\end{tabular}

Some other aspects, however, provide more interesting discussions. First of all, since different values of $\lambda$ yield changes on $\omega_{h}$ and $c_{h}$, then for each case one should expect not only different values of $\delta^{*}$, but also of $\delta^{E}$ and $\hat{\delta}$, i.e., each firm's decision would change according to the value of $\lambda$.

More specifically, one can notice for instance that $\delta^{E}$ increases monotonically with $\lambda$, which is indeed a very intuitive result. In fact, this pattern of $\delta^{E}$ implies that when the infrastructure available is not satisfactory (i.e., when $\lambda$ is large), the government would only be able to attract another firm to the market if it offers a sufficiently high level of incentives. This explanation is pretty reasonable if one considers that, in practice, the entrant firm actually bases its decision to enter or not on its potential profits given a bundle of factors (tax incentives and infrastructure in this case) offered by a country or region. Thus, in this sense, it is reasonable to consider that the government will try to compensate a poor infrastructure with a higher level of incentives.

The incumbent's decision to fight or to accommodate the entry also depends on the existing infrastructure, as mentioned before. In particular, it seems that the worse the existing infrastructure becomes, the more incentives the incumbent firm will have to fight the entry in each case (i.e., $\hat{\delta}$ increases fast as $\lambda$ changes). When $\lambda=2$, for example, the incumbent firm will decide to fight the entry whenever $0<\delta<\hat{\delta}=1.14$. Notice that the value of $\hat{\delta}$ is reasonably greater than $\bar{\delta}$, which implies that this strategy in question will be chosen for any level of incentives that the government decides to concede in this case.

Finally, in each case the government should evaluate the optimal level of incentives to grant according to the expected reactions of the firms. More specifically, as $\lambda$ increases, since the incumbent will have more incentives to fight the entry, then the government should actually offer the minimum amount of incentives possible in order to maximize welfare. And, in these cases, the outcome of the game will be given by $\{e, f\}$.

\section{Concluding Remarks}

The simple model and numerical example presented in 
this paper indicated that the adoption of tax incentives as development policy tools can cause very important effects in a developing region. The productive structure could be heavily changed and production could increase improving conditions to consumers that benefit from the larger output and lower prices. Furthermore, the need for strategic action by the government in order to increase the chance of success of their development strategies is also emphasized, especially if one considers that firms often behave that way.

Probably, the key for the success of this type of policy in the long run lies on the association of tax incentives schemes with the expansion and improvement of the existing infrastructure, especially when it is considered the case where the new firms attracted to the market are small. Certainly, if long-run objectives are considered, it increases even further the need for strategic action by the government. And, the model presented gives good insights on how the government should behave.

\section{REFERENCES}

[1] R. Barro and X. Sala-i-Martin, "Public Finance in Models of Economic Growth," Review of Economic Studies, Vol. 59, No. 4, 1992, pp. 645-661. doi:10.2307/136012

[2] D. Rowlands, "Regional Development in Canada: Problems and Prospects," Canadian Journal of Economics, Vol. 29, No. 1, 1996, pp. S340-S343. doi: $10.2307 / 1925838$

[3] G. T. Sav, "Micro Engineering Foundations of EnergyCapital Complementarity: Solar Domestic Water Heaters," Review of Economics and Statistics, Vol. 66, No. 2, 1984, pp. 334-338. doi:10.2307/1925838

[4] B. Siegel, "Fiscal Incentives and the Economic Development Game," LBJ Journal of Public Affairs, Vol. 9, No. 1, 1997.

[5] R. Kanbur and M. Keen, "Jeux Sans Frontières: Tax Competition and Tax Coordination When Countries Differ in Size," American Economic Review, Vol. 83, No. 4, 1993, pp. 877-892.
[6] A. K. Dixit, "A Model of Duopoly Suggesting a Theory of Entry Barriers," Bell Journal of Economics, Vol. 10, No. 1, 1979, pp. 20-32. doi:10.2307/3003317

[7] A. K. Dixit, "The Role of Investment in Entry-Deterrence," Economic Journal, Vol. 90, No. 357, 1980, pp. 95 106. doi: $10.2307 / 2231658$

[8] D. Fudenberg and J. Tirole, "Game Theory," MIT Press, Cambridge, 1991.

[9] G. Romp, "Game Theory: Introduction and Applications," Oxford University Press, Oxford, 1997.

[10] A. M. Spence, "Investment Strategy and Growth in a New Market," Bell Journal of Economics, Vol. 10, No. 1, 1979, pp. 1-19. doi: $10.2307 / 3003316$

[11] J. J. Gabszwicz, "Strategic Interaction and Markets," Oxford University Press, Oxford, 1999.

[12] J. Tirole, "The Theory of Industrial Organization," MIT Press, Cambridge, 1997.

[13] C. A. G. Nogueira and P. M. Jorge Neto, "Os Impactos Dos Incentivos Fiscais Sobre a Estrutura Industrial e Sobre a Competitividade das Firmas," Revista Econômica do Nordeste, Vol. 29, 1998, pp. 1087-1100.

[14] Y. Ohsawa, "Cross-Border Shopping and Commodity Tax Competition among Governments," Regional Science and Urban Economics, Vol. 29, No. 1, 1999, pp. 33-51. doi:10.1016/S0166-0462(97)00028-8

[15] R. Gibbons, "Game Theory for Applied Economists," Princeton University Press, Princeton, 1992.

[16] J. J. Laffont and J. Tirole, "A theory of Incentives in Procurement and Regulation," MIT Press, Cambridge, 1993.

[17] A. Atkinson and J. Stiglitz, "Lectures on Public Economics," McGraw-Hill, New York, 1980.

[18] E. S. Debaco and P. M. J. Neto, "Competição Entre os Estados por Investimentos Privados," Graduate Program in Economics/Federal University of Ceara, Fortaleza, Working Paper No. 180, 1998.

[19] I. King, R. P. McAfee and L. Welling, "Industrial Blackmail: Dynamic Tax Competition and Public Investment," Canadian Journal of Economics, Vol. 26, No. 3, 1993, pp. 590-608. doi:10.2307/135889 